2 Secondary adoption of technology standards:

3 The case of PREMIS

Devan Ray Donaldson • Elizabeth Yakel

5

(C) Springer Science+Business Media B.V. 2012

\begin{abstract}
While archival scholars have identified some of the most important steps for deciding to use and implement metadata standards in archives, very little systematic empirical investigation within the archival science literature regards either how implementation processes actually unfold or the factors affecting implementation. This article analyzes the organizational factors and processes that come into play during implementation of metadata standards, using PREservation metadata: implementation strategies (PREMIS) as an exemplar. Adapting a theoretical framework for secondary adoption of technologies from Gallivan (Database Adv Inf Syst 32(3):51, 2001), the authors apply their model to the PREMIS technology standard and investigate PREMIS implementation by projects/programs on the Library of Congress PREMIS Implementation Registry. Using data from a series of in-depth semi-structured interviews, the authors develop a model for the secondary adoption of PREMIS and outline implications for the secondary adoption of technology standards based on the results of this study.
\end{abstract}

Keywords Digital curation - Digital preservation - Implementation · PREMIS · Preservation metadata $\cdot$ Secondary adoption $\cdot$ Standards

\title{
Introduction
}

Standards in archives are ubiquitous. They reflect the most current knowledge about professional practices and increase interoperability, consistency, and the safety and security of collections. For archivists working in the digital realm, the pace of standards introduction is swift and the decision to adopt a given standard can mean

D. R. Donaldson $(\square) \cdot$ E. Yakel

School of Information, University of Michigan, 3339A North Quad, 105 S. State St., Ann Arbor, MI 48109-1285, USA

e-mail: devand@umich.edu

\begin{tabular}{|l|llll|}
\hline & Journal : Small-ext 10502 & Dispatch : 24-4-2012 & Pages : 29 \\
Article No. : 9179 & $\square$ LE & $\square$ TYPESET \\
MS Code : ARCS183 & $\square$ CP & $\square$ DISK \\
\hline
\end{tabular}


altering work processes and/or reconfiguring present technologies during the implementation process (Hofman 2005). Because implementation of standards usually entails these more broad-based changes, standards can be ignored or diffusion may progress slowly as repositories adapt in anticipation of adoption.

Archives, libraries, museums, and other cultural heritage organizations that accept responsibility for digital preservation also accept the challenge of implementing preservation systems that conform to emerging standards and best practices (Conway 1996). Metadata standards promulgated by archivists include information about the physical attributes of a record, as well as data about the context of a record's creation, its creator, the business process from which it emanated and information about its structural components (Duff 2004 p 27). Concerns over the long-term maintenance of digital objects have resulted in a growing interest in preservation metadata (Duff 2004; Wilson 2004), and the digital preservation community has responded to these concerns by creating standards for preservation metadata, the most influential standard being PREservation metadata: implementation strategies (PREMIS).

Archival scholars have identified some of the most important steps for deciding to use and implement metadata standards in archives. First, one should consider who developed the metadata standard, why it was developed, to which entities it relates, and what functions it supports (Duff 2004, pp 28-29). Second, an institution should consider its organizational context and how the standard fits into that context and adapt the standard accordingly (Wilson 2004). In addition, institutions must create application profiles, which formally declare how they intend to implement the metadata standards (Wilson 2004). None of these activities are trivial and without challenges, particularly for institutions wishing to make the most of metadata standards for their own management of digital objects while increasing interoperability and consistency among repositories.

Through their own research and experience, archival scholars and practitioners are aware of some of the issues that arise when trying to implement metadata standards after making the initial decision to adopt. However, very little systematic empirical investigation within the archival science literature regards either how implementation processes actually unfold or the factors affecting implementation. Empirically tested conceptual frameworks in diffusion of innovations (DOI) and management and information science (MIS) address issues related to adoption and implementation of information technology broadly defined and could therefore be useful for understanding challenges and opportunities for implementing standards. Because reliable, authentic digital objects will not be preserved across time without adequate preservation metadata, that is, information about the technical environment in which records are created and exist (Duff 2004 p 27), and metadata are essential for the authenticity, preservation, and use of a digital object, a deeper understanding of the factors and processes that constitute metadata standard implementation is crucial. Rather than reinventing the wheel of "factor" and "process" theoretical frameworks and models to better understand implementation from a methodological perspective, archivists ought to draw on those established frameworks and models and adapt that work to suit their own purposes-which is what this article attempts to do.

\begin{tabular}{|l|llll|}
\hline & Journal : Small-ext 10502 & Dispatch : $\mathbf{2 4 - 4 - 2 0 1 2}$ & Pages : 29 \\
Article No. : $: 9179$ & $\square \quad$ LE & $\square$ & TYPESET \\
MS Code : ARCS183 & $\square$ CP & $\square$ DISK \\
\hline
\end{tabular}


In diffusion of innovations (DOI) literature, the initial decision to adopt is known as primary adoption, and secondary adoption is the subsequent process, whereby implementation actually occurs (i.e., resources are allocated, existing systems are adapted or done away with altogether, etc.) (Zaltman et al. 1973). The factors affecting primary adoption and secondary adoption differ (Zaltman et al. 1973). Furthermore, high numbers of primary adopters do not necessarily ensure high numbers of successful secondary adopters (Fichman and Kemerer 1999).

DOI theory offers many "stage research models" (Prescott and Conger 1995) to explain organizational adoption and implementation as well as factors that have been identified (Davis et al. 1989) as playing a role in explaining individuals' behavioral intentions to adopt. Stage research models "identify the sequences of events that occur during implementation - with most stages focused on events following the adoption decision" (Gallivan 2001 p 58). As Gallivan (2001) points out, stage models are a sub-type of "process research models," and like other process models, are valuable in describing how implementation processes unfold, with a focus on the time ordering of events and identification of the events and conditions necessary for certain outcomes to occur (p 58). More recently, researchers have argued that, in cases where primary adoption has already taken place and secondary adoption is not complete, the most appropriate theoretical frameworks to study this particular phenomenon are hybrid models which combine processes and factors because both affect secondary adoption (Shaw and Jarvenpaa 1997). Gallivan's (2001) hybrid model highlights secondary adoption particularly well using factors (e.g., managerial interventions, subjective norms, and facilitating conditions) and processes (e.g., initiation, adoption, adaptation, acceptance, routinization, and infusion) (see center of Fig. 1).

Managerial interventions (Leonard-Barton and Deschamps 1988; Agarwal 2000) are "actions taken and resources made available by managers" to facilitate secondary adoption, including policy decisions such as mandating usage, providing training, and providing support (Gallivan 2001 p 61). Subjective norms describe individuals' beliefs concerning what colleagues expect of them during implementation (Gallivan $2001 \mathrm{p} \mathrm{61)}$. These norms vary depending on the innovation and adoption context (Ajzen and Fishbein 1980; Davis et al. 1989). They "shape potential adopters' understandings about when and why an innovation is being adopted, how much effort to undertake on their own to learn it, or when to abandon the technology for an even newer innovation" (Gallivan $2001 \mathrm{p}$ 61). Facilitating conditions are factors that make implementation more or less likely to occur (Orlikowski 1993). These include "specific attributes of the innovation, the organizational context and culture, and the work task itself" (Gallivan 2001 p 61). Innovation attributes are characteristics of an innovation that make it more or less likely for the innovation to be implemented (Gallivan 2001 p 61). For example, interoperability with other systems and technologies as well as cost could all be seen as innovation attributes. Organization attributes are characteristics of an organization that make an innovation more or less likely to be implemented (Gallivan 2001, p 61). Such attributes can be technological, cultural and/or be related to organizational context. For example, from a technological standpoint, if an organization has flexible technological systems in place, it may well be easier for that organization to implement an innovation by integrating it within

\begin{tabular}{|l|llll|}
\hline & Journal : Small-ext 10502 & Dispatch : $\mathbf{2 4 - 4 - 2 0 1 2}$ & Pages : 29 \\
Article No. : $: 9179$ & $\square$ LE & $\square$ & TYPESET \\
& MS Code : ARCS183 & $\square$ CP & $\square$ & DISK \\
\hline
\end{tabular}




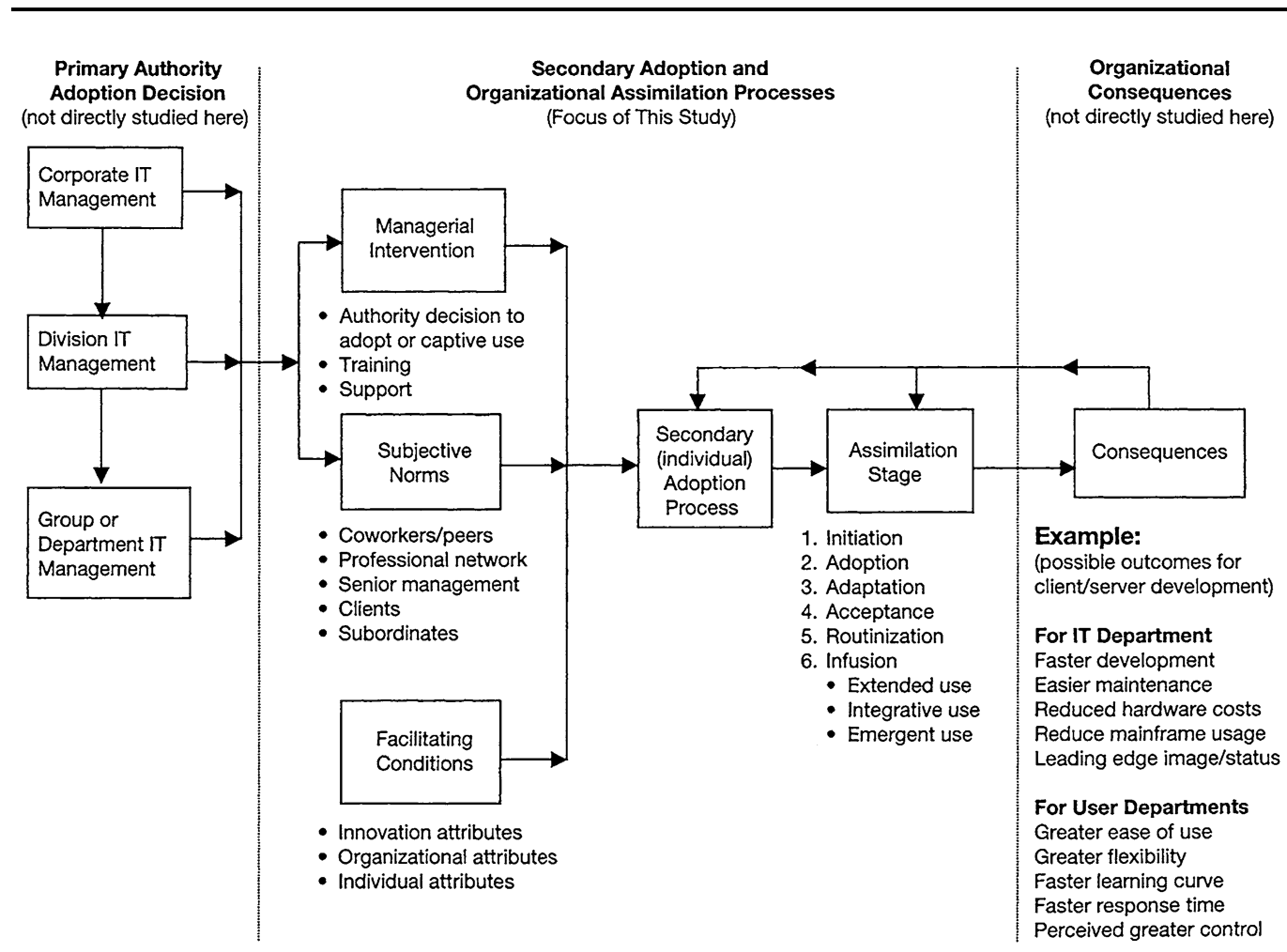

Fig. 1 From Gallivan (2001 p 60)

121 existing systems. Individual attributes are characteristics of individuals within an 122 organization that make an innovation more or less likely to be implemented (Gallivan 123 2001, p 61). The individuals responsible for implementing an innovation within an 124 organization can affect implementation, for example, by their motivation (or lack thereof) in learning about the innovation or their technical and social skills.

Gallivan's framework also incorporates Cooper and Zmud (1990) information technology (IT) implementation process model which occurs in the midst of the assimilation stage ${ }^{1}$ and lists determinants of whether an innovation is fully implemented in the secondary adoption phase. The IT process model includes six stages: initiation, adoption, adaptation, acceptance, routinization, and infusion (pp 131 124-125):

- Initiation refers to a process by which active and/or passive scanning of organizational problems/opportunities and the IT solution are undertaken. Pressure to change evolves from either organizational need (pull), technological innovation (push), or both.

- Adoption refers to rational and political negotiations which ensue to get organizational backing for implementation of an IT application.

- Adaptation occurs when the IT application is developed, installed and maintained. Organizational procedures are revised and developed. Organizational members

\begin{tabular}{|l|llll|}
\hline & Journal : Small-ext 10502 & Dispatch : $\mathbf{2 4 - 4 - 2 0 1 2}$ & Pages : 29 \\
Article No. : $\mathbf{9 1 7 9}$ & $\square \quad$ LE & $\square$ & TYPESET \\
MS Code : ARCS183 & $\square$ CP & $\square$ DISK \\
\hline
\end{tabular}


140 are trained both in the new procedures and in the IT application, and the IT application is available for use in the organization.

- Acceptance occurs when organizational members are induced to commit to IT application usage and the IT application is employed in organizational work.

- Routinization is a process in which usage of the IT application is encouraged as a normal activity and the organization's governance systems are adjusted to account for the IT application; the IT application is no longer perceived as something out of the ordinary.

- Infusion is when increased organizational effectiveness is obtained by using the IT application in a more comprehensive and integrated manner to support higher level aspects of work.

151 If stages within Gallivan's model are thought of as activities, some of which may occur in parallel, the model can encompass a variety of IT applications and implementation processes observed in many organizations (Cooper and Zmud 1990, pp 124-125; Gallivan 2001). Overall, Gallivan's framework combines some constructs from traditional individual adoption models with features of process and stage research models of organizational-level implementation and thus presents a framework "that can explain the interplay among organizational context variables, attributes of managers' implementation strategies, and other characteristics that, in aggregate, shape secondary adoption processes and outcomes" ( $p$ 78). Gallivan's (2001) model is one of the most highly cited models in DOI and MIS literature that brings together key factors and processes from some of the most highly cited empirically tested theoretical frameworks to better explain the socio-technical nature of implementation and was chosen in this article as an appropriate lens to analyze the implementation scenario of technology standards in archives.

In this article, we focus on the organizational factors and processes that come into play during implementation and the interplay among these elements that influence (positively or negatively) full adoption of a technology standard, using PREMIS as an example, by asking: what happens after institutions make the initial decision to adopt a technology standard? We do this through a series of semi-structured interviews with representatives of eleven of the thirteen projects/programs on the Library of Congress PREMIS Implementation Registry. We conclude with a model for the secondary adoption of PREMIS and outline implications for the secondary adoption of technology standards based on the results of this study.

\section{The origins of PREMIS}

176

177

178

179

180
John Garrett and Donald Waters (1996) first articulated the need for trustworthy digital repositories to preserve culturally significant digital objects by maintaining their integrity and authenticity. Garrett and Waters challenged the digital preservation community to create trusted digital repositories because they found that "as stakeholders disseminate, use, reuse, recreate and re-disseminate various

\begin{tabular}{|l|llll|}
\hline & Journal : Small-ext 10502 & Dispatch : $\mathbf{2 4 - 4 - 2 0 1 2}$ & Pages : 29 \\
Article No. : $: 9179$ & $\square$ LE & $\square$ & TYPESET \\
& MS Code : ARCS183 & $\square$ CP & $\square$ & DISK \\
\hline
\end{tabular}


181 kinds of digital information, they can easily, even inadvertently, destroy valuable 182 information" (p 19).

183 Garrett and Waters significantly contributed to an understanding of digital 184 preservation by outlining the elements of a theory of information integrity requiring the preservation of specific features of digital information, including: content, fixity, reference, provenance, and context. The Consultative Committee for Space Data Systems (CCSDS) (2002) proposed the open archival information system (OAIS) reference model and adopted this model of integrity as the centerpiece of its definition of preservation description information.

The Online Computer Library Center/Research Libraries Group (OCLC/RLG) Working Group on Preservation Metadata (2002) mapped a set of metadata elements to reflect the concepts and requirements set forth in the OAIS model. The working group defined the role of preservation metadata within the context of the OAIS model's "Content Information" construct, which consists of a digital object and its associated representation information needed to make a digital object understandable to its designated community (CCSDS 2002 p 2-5). The PREMIS Working Group (2005) took a further step in defining preservation metadata by proposing a data dictionary and an extensible markup language (XML) schema to support implementation of the data dictionary in digital archiving systems. The PREMIS data dictionary and accompanying schema consist of entities and semantic units. PREMIS entities are "things" (i.e., intellectual entities, objects, events, agents, and rights) that are considered important to talk about in the context of a digital preservation repository system" (Caplan 2009 p 7). Semantic units are "pieces of information or knowledge related to PREMIS entities that digital repository systems need to know and should be able to export to other systems" (Caplan 2009 p 7). After version 1.0 of the PREMIS data dictionary and schema were released in 2005, the PREMIS Editorial Committee was formed to gather feedback from the digital preservation community regarding PREMIS and to keep the data dictionary and schema up to date. So far, two updated versions of PREMIS have been released, in 2008 (i.e., version 2.0) and 2011 (i.e., version 2.1), respectively.

PREMIS by itself is an information model that has no direct link to preservation practice unless the model is embedded in a working preservation system. Institutions wishing to take full advantage of the power of PREMIS to define preservation metadata to manage their digital objects must have a digital repository management system in place and make a commitment to utilize PREMIS within it.

PREMIS implementation in the literature

218 The PREMIS data dictionary is implementation independent, meaning the core 219 metadata define information that a repository needs to know, regardless of how, or even whether, that information is stored (PREMIS Editorial Committee 2011 p 4). In addition, an institution does not have to adopt the entire PREMIS data dictionary in order to be considered a PREMIS implementer. The PREMIS Editorial Committee (2010) only requires that whichever entities and semantic units an institution uses be defined according to definitions provided in the data dictionary.

\begin{tabular}{|l|llll|}
\hline & Journal : Small-ext 10502 & Dispatch : $\mathbf{2 4 - 4 - 2 0 1 2}$ & Pages : 29 \\
Article No. : $\mathbf{9 1 7 9}$ & $\square \quad$ LE & $\square$ & TYPESET \\
MS Code : ARCS183 & $\square$ CP & $\square$ DISK \\
\hline
\end{tabular}


225 Regardless of the great flexibility the PREMIS Editorial Committee allows, how institutions go about implementing PREMIS is still important to research because those choices have a direct effect on the digital objects preservation metadata are created for and also have implications for interoperability and consistency among repositories.

While there are many case studies which focus on a particular institution's experience with PREMIS implementation (e.g., Dappert and Enders 2008), only a handful of research articles present specific data on the PREMIS implementation process or speculate on the barriers that may affect implementation. WoodyardRobinson (2007) focuses on how institutions implement the PREMIS data dictionary. Alemneh (2009) explores the barriers to adoption of PREMIS in cultural heritage institutions. In a qualitative case study analysis, Donaldson and Conway (2010) examine a digital archive during its process of PREMIS implementation.

At the time Woodyard-Robinson (2007) wrote, most of the institutions she described were still in the planning stages of preservation metadata implementation; a few had started development, some had mapped their existing metadata to the PREMIS data dictionary; and many were planning further development to their current systems - specifically by integrating the PREMIS data dictionary into their systems. She examined sixteen institutions and uncovered specific information about which PREMIS entities and semantic units implementing institutions were using or planning to use. Her results suggest that the most important decisions regarding PREMIS implementation concern choosing entities and semantic units, gathering appropriate information corresponding to PREMIS entities and semantic units and representing this information in a repository system. However, her study says little about the actual nature or pattern of this decision-making process. Alemneh (2009) suggests that many institutions were waiting for the PREMIS Editorial Committee to release the second version of the data dictionary and XML schema before adopting PREMIS. Beyond this, the most frequently identified barriers to the adoption of PREMIS include lack of training/expertise and perceived lack of knowledge to confidently implement PREMIS (Alemneh 2009 pp 115-117). This study also finds that while many institutions have made the decision to adopt PREMIS, few have fully done so (Alemneh 2009 p 117). While Alemneh's study identifies barriers to the adoption of PREMIS, it does not focus on actual PREMIS implementation, either the processes that embody it or the factors that affect it.

To examine the PREMIS implementation process, Donaldson and Conway (2010) conducted a qualitative case study analysis of the Florida Digital Archive while it was in the middle of PREMIS implementation. They found that adaptation was central to PREMIS implementation. During implementation, the Florida Digital Archive had to adapt its preservation repository management system to use PREMIS effectively: this iterative process involved collaboration among programmers and project managers (p 286). While Donaldson and Conway focused on understanding the PREMIS implementation process, they did not focus on how or which factors and processes affected each other during implementation and their examination was limited to the Florida Digital Archive's experience.

\begin{tabular}{|l|llll|}
\hline & Journal : Small-ext 10502 & Dispatch : 24-4-2012 & Pages : 29 \\
Article No. : 9179 & $\square$ LE & $\square$ TYPESET \\
MS Code : ARCS183 & $\square$ CP & $\square$ DISK \\
\hline
\end{tabular}


In order to implement any metadata standard, institutions must create organizational application profiles, which formally outline the elements from existing metadata schemas an organization uses in metadata implementation (Wilson 2004). For PREMIS, typical application profiles involve use of PREMIS in METS (Guenther and Xie 2007; Vermaaten 2010). Institutions using PREMIS in METS are encouraged to register their profiles on the METS website hosted by the Library of Congress. As of March 2012, 7 institutions have registered their application profiles (Library of Congress 2011). These application profiles can be challenging for institutions to create because there are so many choices that have to be made in order to decide how to encode what preservation metadata is needed. Because PREMIS is so flexible and institutions can choose which entities and semantic units they want to include in their application profiles, this flexibility is both a blessing and a curse. On one hand, institutions interested in using PREMIS in their preservation systems can benefit from looking at other institutions' profiles before formulating their own. In this respect, viewing other institutions' profiles can give institutions ideas about how to create their own. On the other hand, the fact that application profiles vary so much can make it difficult for institutions to reuse others' profiles.

While technological difficulties no doubt pose barriers for the implementation of PREMIS, the reasons why standards are difficult to implement reach beyond technological factors solely. As such, there is a gap in the archival science research literature in understanding the implementation of metadata standards from a methodological perspective as a socio-technical process. This article seeks to address the identified gap in the literature by drawing upon an empirically tested and firmly established theoretical framework from the DOI/MIS literature, Michael J. Gallivan's (2001) model for secondary adoption and organizational assimilation processes, using this model as a guide to ask the following research questions:

1. From the perspective of secondary adopters, what happens during secondary adoption of a technology standard?

2. What processes occur during secondary adoption of technology standards? What factors influence these processes, and what is their effect?

\section{Methodology}

302

We used a qualitative methodology informed by Gallivan (2001) to investigate secondary adoption of PREMIS. This section discusses the rationale for the selection of our study population as well as the methods used to recruit participants, conduct interviews, and analyze the resulting data.

\section{Rationale for the choice of study population}

307 Since we were interested in the issues associated with secondary adoption, we 308 identified the Library of Congress PREMIS Implementation Registry as a good 309 population with which to begin our inquiry. This group was selected for several

\begin{tabular}{|l|llll|}
\hline & Journal : Small-ext 10502 & Dispatch : $\mathbf{2 4 - 4 - 2 0 1 2}$ & Pages : 29 \\
Article No. : $: 9179$ & $\square$ LE & $\square$ & TYPESET \\
& MS Code : ARCS183 & $\square$ CP & $\square$ & DISK \\
\hline
\end{tabular}


310 reasons. First, the registrants self-identify as engaged in the implementation process.

311 Second, one of the goals of this study was to identify and understand in-depth the 312 factors associated with PREMIS implementation. We assumed that organizations that publicly identified themselves might be more willing to reflect on their experiences and clarify all the dimensions of implementation. Third, although only thirteen projects/programs are on the registry, they are diverse. Participants in the registry include eight universities, four national archives or libraries, one statewide consortium, and one commercial vendor. They are from four countries, and the data preserved in the repositories spans textual resources, audio files, images, and scientific research data sets. Finally, we judged that the projects/programs (Kenney and Rieger 2000) were in different stages of the implementation process given their varied status as projects, programs, or transitioning from projects to programs. While our dataset is small, it does provide an in-depth examination of PREMIS adoption in a diverse group of organizations.

Recruiting participants

325

326

327

328

329

330

331

332

333

Beginning in mid-January 2010, the first author contacted the designated representatives for all thirteen projects/programs listed on the PREMIS Implementation Registry by email and asked for a telephone interview. If that person indicated that s/he was not responsible for PREMIS implementation at the organization, we asked that person to forward the recruitment email to those who were. In the end, thirteen participants from eleven organizations representing ten projects/programs agreed to participate in this study. The eleven organizations represented ten projects/programs because one of the projects/programs involved a collaboration between two organizations (i.e., the commercial vendor and an organization).

\section{Data collection/interview protocol}

We conducted semi-structured 45-min audio-taped interviews over the telephone. The interview protocol (see "Appendix") is divided into two sections. "Introduction" focused broadly on management practices, the business and technology drivers underlying these practices, and the context and culture of each cultural heritage organization. "Background" captured information about each organization's objectives for adopting PREMIS, their implementation process, and approaches for retraining existing employees, hiring new employees, and/or outsourcing aspects of PREMIS implementation. For "Introduction", the interview data were collected and analyzed without any particular theoretical framework in mind, however, for "Background", Gallivan's (2001) framework provided a highlevel lens to guide interviews and structure data analysis. The constructs in the center of Fig. 1 were perceived as rather broad, and therefore, more specific examples of secondary adoption factors and processes were sought to illustrate these constructs. For this reason, subjects were asked about policies, key milestones, resources, participants, as well as critical events, obstacles, or surprises that they perceived to be significant to implementation.

\begin{tabular}{|l|llll|}
\hline & Journal : Small-ext 10502 & Dispatch : $\mathbf{2 4 - 4 - 2 0 1 2}$ & Pages : 29 \\
Article No. : $: 9179$ & $\square$ LE & $\square$ & TYPESET \\
& MS Code : ARCS183 & $\square$ CP & $\square$ & DISK \\
\hline
\end{tabular}


The individuals responsible for PREMIS implementation at Organizations 7 and 11 were unable to conduct interviews over the telephone. In these cases, the first author emailed each representative the interview protocol and the individuals replied with responses to all of the questions.

Data analysis

Following each interview, detailed transcripts were prepared, the interview data were compared with the factor and process constructs in Gallivan's framework, and key themes were identified through the coding process. As interview results accumulated, analytical induction methods (Miles and Huberman 1994) were used to identify themes that were important to the implementation process at each institution. Isolating these themes required dialogical reasoning (Klein and Myers 1999) or constant iteration between the data and Gallivan's framework. Next, the constant comparative method (Corbin and Strauss 2008) was used to identify similarities and differences across institutions, and several key themes were found to be relevant for explaining the observed processes and outcomes in the various institutions.

In the findings section, we place factor and process constructs from Gallivan's framework within the context of secondary adoption of PREMIS, and in the discussion section, we present the themes that emerged from the data and propose a model for the secondary adoption of PREMIS. We also speculate on the extent to which secondary adoption of PREMIS can relate to secondary adoption of other technology standards.

\section{Findings}

This section presents information about study participants and then takes each of Gallivan's factor and process constructs, providing evidence from the data to show how each construct is instantiated in an organization. Since this qualitative research study did not address the primary decision-making process concerning PREMIS adoption, this study focuses on the "secondary adoption and organizational assimilation processes" comprising the center of Fig. 1. As such, after a description of the sample interviewed, we discuss three factors (managerial interventions, subjective norms, and facilitating conditions) and six process-related elements (initiation, adoption, adaptation, acceptance, routinization, and infusion). In addition, we present and discuss a seventh process-related element we found, experimentation, which also was a critical dimension of PREMIS secondary adoption.

\section{Study participants}

This study captured seventy-seven percent (i.e., ten of thirteen) of the entire population of registered PREMIS projects and programs (PREMIS Maintenance Activity 2010). Of the organizations included in this study (See Table 1), four were

\begin{tabular}{|l|llll|}
\hline & Journal : Small-ext 10502 & Dispatch : $\mathbf{2 4 - 4 - 2 0 1 2}$ & Pages : 29 \\
Article No. : $: 9179$ & $\square$ LE & $\square$ & TYPESET \\
& MS Code : ARCS183 & $\square$ CP & $\square$ & DISK \\
\hline
\end{tabular}


Table 1 Participating organizations

\begin{tabular}{|c|c|c|c|}
\hline Participants (P) & Organization $(\mathrm{O})$ & Organization type & Implementation type \\
\hline $\mathrm{P} \mathrm{O} 1^{\mathrm{a}}$ & Organization 1 (O1) & University & Project/full program \\
\hline $\mathrm{P} 2 \mathrm{O} 2, \mathrm{P} 3 \mathrm{O} 2$ & Organization 2 (O2) & National archive or library & Full program \\
\hline $\mathrm{P} 4 \mathrm{O} 3, \mathrm{P} 5 \mathrm{O} 3$ & Organization 3 (O3) & University & Full program \\
\hline $\mathrm{P} 6 \mathrm{O} 4$ & Organization 4 (O4) & University & Project \\
\hline P7O5 & Organization 5 (O5) & National archive or library & Project \\
\hline P8O6 & Organization 6 (O6) & University & Project/full program \\
\hline P9O7 & Organization 7 (O7) & National archive or library & Full program \\
\hline $\mathrm{P} 10 \mathrm{O} 8$ & Organization 8 (O8) & Commercial vendor & Project \\
\hline P1109 & Organization (O9) & University research center & Project/full program \\
\hline $\mathrm{P} 12 \mathrm{O} 10$ & Organization (O10) & Consortium & Full program \\
\hline P13011 & Organization (O11) & National archive or library & Full program \\
\hline
\end{tabular}

${ }^{a}$ The numbering scheme is used to uniquely identify each participant interviewed in this study by giving each participant a number and a link to each participant's organization. For example, Participant 1 (P1) works for Organization (O1)-hence P1O1.

national archives or libraries, four were universities, one was a commercial vendor, one was a consortium, and one was a university research center. One of the organizations included in this study, Organization 2 (O2), was a client of the commercial vendor, Organization 8 (O8), and used the vendor's product in their effort to implement PREMIS. Thus, $\mathrm{O} 2$ and $\mathrm{O} 8$ represent one program on the PREMIS Implementation Registry. Organizations 1, 6, and 9 had experience implementing PREMIS in project and full program contexts. Organizations 2, 3, 7 , 10 , and 11 had experience in full program implementation of PREMIS. Organizations 4, 5, and 8 only had experience implementing PREMIS in a project context.

\section{Factor construct: Managerial interventions}

Managerial interventions are "actions taken and resources made available by managers" to facilitate secondary adoption, including policy decisions such as mandating usage, providing training, and providing support (Gallivan 2001 p 61). Participants in this study cited several examples of managerial interventions. At several sites $(\mathrm{O} 1, \mathrm{O} 2, \mathrm{O} 3, \mathrm{O} 4, \mathrm{O} 7, \mathrm{O} 10$, and $\mathrm{O} 11)$, managers making the primary decision to adopt PREMIS engaged in high-level discussions about implementing PREMIS with select staff. This suggests that managers assessed the ability of their organizations to implement PREMIS during primary adoption. Often, one result of these consultations was a managerial decision to add additional resources, specifically staff with project management and programming skills, to expedite implementation. For example, managers at Organizations 2 and 3 hired staff to help with PREMIS implementation. Interviewees $\mathrm{P} 2 \mathrm{O} 2$ and $\mathrm{P} 4 \mathrm{O} 3$ described their expertise in programming, and they both noted the necessity of this skill. $\mathrm{P} 3 \mathrm{O} 2$ and $\mathrm{P} 5 \mathrm{O} 3$ possessed project management skills, as evidenced by their years of experience working in libraries addressing various information systems issues. These were all new hires to support

\begin{tabular}{|l|llll|}
\hline & Journal : Small-ext 10502 & Dispatch : 24-4-2012 & Pages : 29 \\
Article No. : 9179 & $\square$ LE & $\square$ TYPESET \\
MS Code : ARCS183 & $\square$ CP & $\square$ DISK \\
\hline
\end{tabular}


PREMIS implementation. The importance of managers hiring employees with programming expertise is perhaps best captured by P5O3's statement; "when it came down to it, [P4O3] was instrumental in actually making [PREMIS implementation] happen, because I think there's a lot of programming that's involved in actually implementing PREMIS functionality into a repository system."

Managerial intervention was also evident at Organization 6 where managers supported staff involvement with community-based PREMIS standard development work:

[P]eople, in terms of upper management, they supported my training, my being involved in the PREMIS Working Group, going to meetings, they supported my travel, and let me spend my time on [PREMIS], and you know, talking with colleagues, and, so, you know, I think there was a lot of support for [PREMIS] (P8O6).

For the managers, the payoff was that P8O6 developed a thorough understanding of PREMIS and was able to make sure that PREMIS development activities suited their organization. Additionally, P8O6 was able to provide clarification to colleagues concerning the rationale behind the PREMIS data dictionary and schema.

\section{Factor construct: Subjective norms}

Subjective norms "describe individuals' beliefs about the expectations of relevant others regarding their own secondary adoption behavior" (Gallivan 2001 p 61). Participants cited subjective norms as influential to secondary adoption of PREMIS. For example, in Organization 2, staff members' beliefs about managers' expectations of them during PREMIS implementation were important. P3O2 noted, "[o]ur boss's boss's boss ... in a meeting here, when she was introducing herself, told us it was okay to fail, but fail quickly. So, that's kind of the attitude, is, we're going to put some stuff in place, and if we fail, the community will benefit from our failure." In this example, the manager gave staff license to try many things, and fail if need be, in order to try to make PREMIS work for their organization. The manager's statement influenced staff members' beliefs about how she expected them to approach PREMIS implementation. This "fail, but fail quickly" endorsement was critical to implementation because, as a result, $\mathrm{P} 2 \mathrm{O} 2$ and $\mathrm{P} 3 \mathrm{O} 2$ were not reluctant to try different things in order to get PREMIS to work-knowing that management recognized the need for experimentation.

Co-workers' expectations of how to approach the task of PREMIS implementation were also key to secondary adoption. In Organization 3, P4O3 stated, "we had these high level goals, and we all agreed about them, and so there was a mindset for the group that we're going to take [adoption] as far as we can, and so the programmers were just as invested ... as the archivists." According to P4O3, the shared belief that everyone was in the PREMIS implementation process together was very motivational. A co-worker (P4O3) noted that his boss also possessed this mindset and provided "enough time and resources." As a result, $\mathrm{P} 4 \mathrm{O} 3$ believed that all of this would lead not only to effective use of PREMIS, but also to better a repository system.

\begin{tabular}{|l|llll|}
\hline & Journal : Small-ext 10502 & Dispatch : $\mathbf{2 4 - 4 - 2 0 1 2}$ & Pages : 29 \\
Article No. : $: 9179$ & $\square$ LE & $\square$ & TYPESET \\
& MS Code : ARCS183 & $\square$ CP & $\square$ & DISK \\
\hline
\end{tabular}


459 Gallivan (2001) identifies facilitating conditions as factors that make implemen460 tation more or less likely to occur, such as specific attributes at the (1) innovation, 461 (2) organization, and (3) individual levels (p 61).

Innovation attributes Innovation attributes are characteristics of an innovation that make it more or less likely for the innovation to be implemented (Gallivan 2001 p 61). Participants cited the ability of PREMIS to complement other technology standards currently used by their organizations as an innovation attribute. Specifically, participants cited use of PREMIS in concert with other metadata standards, including, but not limited to: the metadata encoding and transmission standard (METS) and the metadata for images in XML (MIX) Standard (P1O1, P2O2, P4O3, P6O4, P7O5, P8O6, P907, P1008, P1109, and P12010); encoded archival description (EAD) (P9O7); the metadata object description schema (MODS) Standard (P7O5, P4O3, and P6O4); Dublin Core (P4O3, P3O2, and P10O8); XML digital signatures (P7O5); and the data document initiative II (DDI 2) (P13O11). The fact that PREMIS complemented other metadata standards made it easier for PREMIS to work with existing or developing preservation repository systems.

Organization attributes Organization attributes are characteristics of an organization that make an innovation more or less likely to be implemented (Gallivan 2001 p 61). In some cases, the status of an organization's preservation repository was seen as an organization attribute. Organizations that were in the process of making significant changes to or creating entirely new preservation repository systems and software were well suited to engage in implementation, because these organizations were in the midst of changes and could adapt more easily to PREMIS specifications (P8O6, P1O1, P2O2, P3O2, P4O3, P5O3, P7O5, P11O9, and P10O8). For example, as P1109 stated:

We are in the process of updating our underlying system [...] A few years ago, we decided to start working toward OAIS compliance ... and so we started talking about and thinking about and actually did a few internal projects, to figure out, this actually started before PREMIS was even released, ... what [information] we thought we should be keeping, and then actually, the first thing we did with PREMIS was compare our list of what we thought we should be keeping with what PREMIS had available to see if they were compatible, and they were.

In order to become OAIS compliant, P1109 stated that one of the areas requiring alteration was preservation metadata. P11O9 and her colleagues decided to use PREMIS for the information they needed, and then began the process of implementing it.

System flexibility was another facilitating factor. For example, P4O3 stated that, "in the absence of like, real restrictions from the software we were using, we chose [PREMIS] as a format," and P5O3 stated, "because we were doing something like custom-built here we could use [PREMIS]."

\begin{tabular}{|l|llll|}
\hline & Journal : Small-ext 10502 & Dispatch : 24-4-2012 & Pages : 29 \\
Article No. : 9179 & $\square$ LE & $\square$ TYPESET \\
MS Code : ARCS183 & $\square$ CP & $\square$ DISK \\
\hline
\end{tabular}


499

500

501

502

503

504

505

506

507

508

509

510

511

512

513

514

515

516

517

518

519

520

521

522

523

524

525

526

527

528

529

530

531

532

533

534

535

536

537

538

539

540

Individual attributes Individual attributes are characteristics of individuals within an organization that make an innovation more or less likely to be implemented (Gallivan $2001 \mathrm{p} \mathrm{61)}$. The data suggest that when individuals are motivated to seek out formal and informal mechanisms to deepen their understanding of PREMIS, this has a positive effect on implementation. Seven participants acknowledged that during implementation they joined the PREMIS Implementers' Group listserv (i.e., the PIG list) and utilized this resource by posting messages, reading messages, or both, and they utilized resources on the PREMIS maintenance activity website frequently (P8O6, P9O7, P12O10, P2O2, P3O2, P4O3, and P5O3). Utilizing these resources aided them in implementation at their organizations by being able to ask other listserv members specific questions about implementation and downloading the data dictionary again if ever they lost their copies. Several participants noted that they communicated with PREMIS Working Group and Editorial Committee members and that these interactions were also influential to implementation (P1O1, P3O2, P7O5, P8O6, P10O8, P1109, and P12O10):

[m]e and our application vendor have emailed [one of the PREMIS Editorial Committee Members] with specific questions about PREMIS, you know, what do you guys mean by this? (P3O2)

[o]bviously we have the extra benefit of, at the time, [one of the PREMIS Working Group members] was just down the hall. So, it certainly made discussing PREMIS a lot easier (P7O5).

Similarly, four participants noted that they communicated with implementers at other organizations, and that these interactions were influential to implementation (P1O1, P3O2, P8O6, and P10O8). P2O2 thought talking with implementers at other organizations was particularly useful because he "knew the right people" to talk to and knew that they were "in the same place" in the PREMIS implementation process as he was. By being able to discuss the rationale behind the PREMIS data dictionary and ask questions about specific implementation choices and consequences, participants found reaching out to PREMIS Working Group members, PREMIS Editorial Committee members, and implementers at other organizations helpful in advancing implementation at their organizations.

\section{Process construct: initiation}

Initiation refers to the process of active and/or passive scanning of organizational problems/opportunities and IT solutions (Cooper and Zmud 1990). During this time, pressure to change evolves from either organizational need (pull), technological innovation (push), or both, and, as a result, a match is found between an IT solution and its application in an organization (Cooper and Zmud 1990, p 124). Data from all of the organizations in this study suggest that initiation took place during PREMIS implementation. Participants spoke about the initiation phase in terms of both organizational need (pull), specifically to address digital preservation information needs, and technological innovation (push), in which use of PREMIS was proposed as the solution:

\begin{tabular}{|l|llll|}
\hline & Journal : Small-ext 10502 & Dispatch : $\mathbf{2 4 - 4 - 2 0 1 2}$ & Pages : 29 \\
Article No. : $: 9179$ & $\square$ LE & $\square$ & TYPESET \\
& MS Code : ARCS183 & $\square$ CP & $\square$ & DISK \\
\hline
\end{tabular}


The IT Department saw the need of keeping preservation metadata when implementing applications for digital preservation. It was then decided that PREMIS should be used since it is the most widely accepted standard for preservation metadata (P9O7).

In this example, $\mathrm{P} 907$ describes the pull as the need for keeping preser ation metadata and using PREMIS as the push because it is a widely accepted standard for preservation metadata that staff believed could satisfy Organization 7's needs. In another example, $\mathrm{P} 6 \mathrm{O} 4$ describes pull as the need to develop a packaging profile for the digital objects they preserve and the push as PREMIS because there was no other viable option for use of a standard that was both supported by the Library of Congress and for preservation metadata:

We had this ... system, focused on preservation, and the first thing we decided we needed to do was come up with a packaging profile, and METS seemed to be the natural choice for that ... and ... we settled on PREMIS for preservation metadata, partially [because we were partnering with the Library of Congress, so we wanted to try to use the standards they support], and also because there really wasn't anything else available at the time.

\section{Process construct: Adoption}

560

561

562

563

Adoption refers to the negotiation process which ensues to get organizational backing and to invest the necessary resources throughout the implementation effort (Cooper and Zmud 1990, p 124). Ongoing negotiations were a feature at two of the organizations (P1O1, P11O9). P1O1 stated,

The process we went through, was a process of pairing, starting with what we first thought was going to be of interest [i.e, initiation], and then, driven by the reality, the economic reality of time and money and personnel, we've slimmed down to the point where it's what we can reasonably do automatically. We had to face the reality of the future is going to get only what we are capable of giving the future, and not more, which sounds sort of like a tautology, but we didn't know that in the beginning.

During these discussions at Organization 1, staff realized the economic implications of full program PREMIS deployment and scaled back their plans to better align with organizational resources. During initiation, P1O1 and his colleagues considered how to use PREMIS in light of all they wanted, but during conversations in the adoption process, what was economically feasible became clearer, and these discussions led to decisions to limit the scope of PREMIS use.

During adoption at Organization 9, P1109 and her colleagues discussed and then applied for external funding in order to amass the resources necessary to accommodate PREMIS implementation:

The next step was to get a grant, and the grant was to test and demonstrate implementation of an Archival Information Package. And the Archival Information Package would have data, and it would have, ummm, you know,

\begin{tabular}{|l|llll|}
\hline & Journal : Small-ext 10502 & Dispatch : 24-4-2012 & Pages : 29 \\
Article No. : 9179 & $\square$ LE & $\square$ TYPESET \\
MS Code : ARCS183 & $\square$ CP & $\square$ DISK \\
\hline
\end{tabular}


all that various kinds of metadata, and so that's where the METS, PREMIS, ISO thing came into play, and so that was sort of a demonstration.

Beyond these examples, other participants did not address an adoption process as defined in this sub-section. Perhaps the reason P1O1 mentioned this process is because he had been involved in PREMIS implementation from the onset. In contrast, several other participants in this study (P2O2, P3O2, P4O3, P5O3, P9O7, and P13O11) were hired after PREMIS implementation began at their organizations. As such, these participants may not have mentioned this process during the interviews either because it had already occurred before they were employed or they were not involved in this particular process.

\section{Process construct: Adaptation}

Adaptation is when an innovation is "re-invented so as to accommodate the organization's needs and structure more closely" (Rogers 2003 p 424). Adaptation can also refer to changes in the organization itself as a result of the innovation (Van de Ven 1986; Leonard-Barton 1988). All organizations experienced adaptation.

Adaptation of PREMIS to work with other metadata schemas was most frequently cited. For Organization 2, this type of adaptation seemed to be standard:

They've gone through and adopted a lot of [PREMIS] in a practical application way, and, so, they actually take PREMIS elements and wrap them in with other things like Dublin Core and other types of metadata in a schema that they've developed (P3O2).

Organization 1 finished one project in which PREMIS was adapted to work within METS to represent technical metadata; "[w] e used PREMIS embedded in METS ... and our principle was we didn't want to duplicate any metadata within the METS file. So anything that was covered by METS we excluded from our PREMIS" (P1O1). In a subsequent collaborative project with other organizations, P1O1 adapted PREMIS to track provenance information about digital objects as they are transmitted among the participating organizations. In this project, P1O1 and his colleagues adapted PREMIS to work outside of METS.

In Organization 3, development of the entire repository system and PREMIS implementation went hand in hand. This provides some evidence for organizational changes as a result of PREMIS implementation:

We looked at [the PREMIS] model early on and mapped it to FEDORA in a lot of ways. So I'd say [PREMIS] influenced the design of our FEDORA implementation on a high level, and on a low level, we sort of iteratively improved our events ${ }^{2}$ (P4O3).

\footnotetext{
${ }^{2}$ Here P4O3 is referring to PREMIS events. PREMIS events correspond to the PREMIS event entity which "aggregates information about actions that affect objects in the repository. An accurate and trustworthy record of events is critical for maintaining the digital provenance of an object, which in turn is important in demonstrating the authenticity of the object. The information that can be recorded about events includes: a unique identifier for the event (type and value); the type of event (creation, ingestion,
}

\begin{tabular}{|l|llll|}
\hline & Journal : Small-ext 10502 & Dispatch : $\mathbf{2 4 - 4 - 2 0 1 2}$ & Pages : 29 \\
Article No. : $: 9179$ & $\square$ LE & $\square$ & TYPESET \\
& MS Code : ARCS183 & $\square$ CP & $\square$ DISK \\
\hline
\end{tabular}


621 Acceptance refers to the process in which organizational members are induced to commit to an innovation's usage, and the IT application is employed in organizational work (Cooper and Zmud 1990 p 124). One participant (P7O5) stated that his boss encouraged all employees in his department to use standards, and this, in part, influenced his use of PREMIS. But for the most part, participants used PREMIS because it was a standard $(\mathrm{O} 2, \mathrm{O} 7, \mathrm{O} 11)$. Because participants were not aware of another standard for preservation metadata, there was no alternative, other than inventing or maintaining home-grown, ad hoc means of capturing and representing preservation metadata for their digital objects. The latter part of acceptance, in which the IT application is employed in organizational work, is supported by additional data in "Process construct: routinization".

One participant (P7O5) shared details about why the acceptance process went unfavorably in a full program context at his organization. P7O5 was instrumental in implementing PREMIS in a project context, but decided not to use PREMIS in a full program context based on his project experience. When asked, "[d]oes using PREMIS advance your institution's goals with respect to preservation of digital objects?" P7O5 responded, more easily could have encoded the data we wanted to in our own schema as opposed to using something like PREMIS. PREMIS actually, like METS or

According to P7O5, creating home-grown mechanisms for the capture and representation of preservation metadata was easier than using PREMIS, and he and his colleagues ultimately chose home-grown means of handling preservation metadata. Although Organization 5 did not accept PREMIS at a full program level, P7O5 said that their experience with PREMIS influenced their current practice of placing a lot of emphasis on keeping track of the fixity of files so that they know their attempts at preserving collections are successful.

\section{Process construct: Experimentation}

Experimentation refers to a testing process in which staff test a technology standard on a small scale before attempting to implement it within an organization's systems and use trial and error to assess fit throughout the implementation process. Though this construct was not proposed as part of Gallivan's framework, it is proposed here in response to the data we collected. Nearly, all organizations seeking full program PREMIS implementation (O2, O3, O6, O7, O9, O10) were actively engaged in experimentation at the time of this study.

\begin{tabular}{|l|llll|}
\hline & Journal : Small-ext 10502 & Dispatch : 24-4-2012 & Pages : 29 \\
Article No. : 9179 & $\square$ LE & $\square$ TYPESET \\
MS Code : ARCS183 & $\square$ CP & $\square$ DISK \\
\hline
\end{tabular}


Participants identified experimentation as a critical step occurring before and building directly upon prior implementation processes:

We had a pilot repository that [grew out of our completed project] testbed, where we used essentially the same PREMIS implementation that we had developed as our combination of METS and PREMIS within METS as an object descriptor accompanying each file that we stored. We scrapped that repository and are now building another one (P1O1).

P1O1 took what he learned from the PREMIS project he had completed and applied it to building a pilot repository. He then took what he learned from the experience of building a pilot repository to build a full program repository system. Although he was in the beginning phases of constructing this new repository, he was already making preparations for the role PREMIS would play in it, namely that PREMIS would be used to track specific preservation activities:

At the moment, there is no PREMIS metadata going into [the new] repository because it's still in the building phase. I'm currently building a PREMIS events $^{3}$ database that will track the events that happen within the archive, but outside the archive. So, theoretically, we will end up with technical metadata produced from JHOVE [i.e, JSTOR/Harvard Object Validation Environment], or by descriptive metadata that's produced wherever depending on who creates the objects in the first place, and then there will be [PREMIS] event metadata, along with things like, of course, [PREMIS] agent, ${ }^{4}$ and you know, we'll flesh it out as we can.

Organization 2 was in the experimentation phase. $\mathrm{P} 2 \mathrm{O} 2$ and $\mathrm{P} 3 \mathrm{O} 2$ were in the process of checking the accuracy of PREMIS adaptations related to capturing information about preservation activities (e.g., migration) before moving on to other PREMIS implementation processes:

We are still, this very minute, and this very day, we are still in the process of testing the phase 2 functionality that the developers have given us, which means we are spending a lot of time looking in great detail at the [PREMIS] data model and at what should be happening to populate the data model and how the data model should be driving functionality. [... I mean, just know currently we're in the job of finding defects ... which means it's not fully nailed down yet (P2O2).

Once $\mathrm{P} 2 \mathrm{O} 2$ and $\mathrm{P} 3 \mathrm{O} 2$ ascertain that PREMIS is capturing the information they need it to capture during ingest, they will add new parts of PREMIS to their program. At that point, making further adaptations to their use of PREMIS will be difficult and highly unlikely.

Several participants cited that the experimentation process often involved the creation and testing of use cases (also referred to as prototypes, specifications (i.e., specs), or templates) (P2O2, P7O5, P8O6, and P1109):

\footnotetext{
${ }^{3}$ See footnote 3 .

${ }^{4}$ PREMIS agents are "actors that have roles in events and in rights statements.... Agents can be people, organizations, or software applications" (Caplan 2009 p 11).
}

\begin{tabular}{|l|llll|}
\hline & Journal : Small-ext 10502 & Dispatch : $\mathbf{2 4 - 4 - 2 0 1 2}$ & Pages : 29 \\
Article No. : $: 9179$ & $\square$ LE & $\square$ & TYPESET \\
& MS Code : ARCS183 & $\square$ CP & $\square$ & DISK \\
\hline
\end{tabular}


The defining factor I guess for whether we use PREMIS elements or not within the system is we have to define a use case for it and show how we will use it, would use, and what value it brings for the extra overhead of developing it within the system (P2O2).

We created prototypes with PREMIS for, let's see, it was kind of a two step process, for each type of format. So textual resources was one sort of format. Audio files was another format. Geospatial was another format. So, for each of those formats, there was a prototype, or kind of a spec is what I would call it, that was created. For each project there was an assessment made for how PREMIS would fit that prototype, if that makes sense. So the first project where there was a new format involved more prototyping really than subsequent projects with similar formats (P8O6).

We shared what we called templates, which were example documents that showed and annotated the use of how we would encode our digital objects. So, you know, the thing that people would look at is an example METS record which contained some PREMIS in it used the way we intended to use PREMIS. So that's how we communicated, you know, discussed our use of PREMIS (P7O5).

The creation and testing of these use cases during the experimentation process gave participants valuable preliminary experience in assessing the extent to which they could use PREMIS to capture and represent preservation metadata for the digital objects they preserve without having to use their entire collections or engage their entire program. Participants learned from their experiences during experimentation, which made future adaptations of PREMIS easier and advanced subsequent implementation processes (P1O1, P8O6, P9O7, and P11O9).

\section{Process construct: Routinization}

Routinization refers to a process by which use of an innovation becomes a normal activity; the organization's governance systems, processes, and routines adjust and the IT application is no longer perceived as something out of the ordinary (Cooper and Zmud 1990, p 124). The data suggest that in some organizations, routinization had already taken place (P8O6, P9O7, and P12O10): "Use of PREMIS is implemented in our applications for managing digital preservation. Currently, PREMIS information is created and maintained by our applications ... ingest control and our archival storage system" (P9O7).

In four organizations, routinization had either not yet started or was incomplete (O1, O2, O3, and O9). When asked, "[i]s PREMIS embedded in your organization's preservation systems and protocols?" P1109 responded, "not quite yet." P1109 gave this response because, at her organization, they had successfully completed a proof of concept to demonstrate that PREMIS could represent the information they needed for the kinds of digital objects they preserve, but had not completed the process of "operationalizing" PREMIS within Organization 9's systems. As of the time of this study, Organizations 2 and 3 had not yet routinized PREMIS in their

\begin{tabular}{|l|llll|}
\hline & Journal : Small-ext 10502 & Dispatch : 24-4-2012 & Pages : 29 \\
Article No. : 9179 & $\square$ LE & $\square$ TYPESET \\
MS Code : ARCS183 & $\square$ CP & $\square$ DISK \\
\hline
\end{tabular}


repository systems because they were still testing them, and Organization 1 had not yet routinized PREMIS because P1O1 was in the beginning stages of constructing a new repository along with an accompanying database which would record information about preservation activities using PREMIS.

\section{Process construct: Infusion}

Infusion, in which organizational effectiveness is increased by using an IT application in a more comprehensive and integrated manner to support higher level aspects of work, can be characterized by three different facets: extensive use of an innovation (i.e., using more technology features); more integrative use (i.e., using technology to create new workflow linkages among tasks); and/or emergent use (i.e., using technology to perform tasks not previously considered possible) (Cooper and Zmud 1990 pp 124-125; Saga and Zmud 1994).

No organization in this study uses the PREMIS data dictionary and its accompanying schema in their entirety. However, several organizations use PREMIS extensively by applying their specifications for use of PREMIS to all objects within their projects/programs:

[S]ince 2010, PREMIS metadata is being registered automatically when

[Archival Information Packages] are created and stored in our archival storage systems (P9O7).

[PREMIS] [e]vents are captured as objects pass through the ingest process (P13O11).

We use PREMIS in [our] project for some of the metadata for the digitized [materials] that we collect (P7O5).

The data support both integrative and emergent use of PREMIS. In terms of integrative use, several participants cited use of PREMIS by embedding PREMIS in other metadata standards the organizations used (see "Process construct: adaptation") and placing these formalized adaptations within organizational systems ("Process construct: Routinization"). Emergent use was evidenced when participants discussed use of PREMIS in terms of being able to reach specific preservation goals and document specific preservation activities, including: tracking provenance, representing technical metadata, and linking digital objects to rights information (P1O1, P5O4, P1109, P2O2, and P3O2). For example, when asked, "[d]oes using PREMIS advance your organization's goals with respect to preservation of digital objects?" P8O6 responded, "[y]eah, I really think it does. I mean, I think, particularly when it comes to finding a place to just keep references and keep the basics together, like rights, and like IDs. I think [PREMIS] can be very simple, and automated, and that furthers [our] goals."

Based on interviewee responses, only one organization sought to verify emergent use by seeking assessment from their data providers:

I want to say restoring, but it's not the same sense. Giving back the product, giving back the resource to the original data provider, by reconstituting the digital resource and making sure that we close the loop. You know, that they

\begin{tabular}{|l|llll|}
\hline & Journal : Small-ext 10502 & Dispatch : $\mathbf{2 4 - 4 - 2 0 1 2}$ & Pages : 29 \\
Article No. : $\mathbf{9 1 7 9}$ & $\square \quad$ LE & $\square$ & TYPESET \\
MS Code : ARCS183 & $\square$ CP & $\square$ DISK \\
\hline
\end{tabular}


780

got back what they thought they should be getting back. So PREMIS was critical in that in order to give them back their original name, for instance. I mean, just key. They could run it through their presentation system or whatever they were doing with them. And so I suppose another step of that would be, reconstituting is a step, giving it back to the data provider is a step, and having them reuse it. So, in other words evaluate the reconstituted [...] and then giving feedback to us (P8O6).

According to P8O6, all of the work she and her colleagues did to initiate, adopt, adapt, accept, and routinize PREMIS would be a failure unless the original data providers would be able to reuse the data they provided, and also understand what effect, if any, preservation activities have had on the data they provided since the data became a part of Organization 6's collections.

\section{Discussion}

The purpose of this study was to address the research questions: From the perspective of secondary adopters, what happens during secondary adoption of a technology standard? Specifically, what processes occur during secondary adoption of technology standards? What factors influence these processes, and what is their effect? In particular, we were interested in the organizational factors and processes that come into play during implementation and the interplay among these elements that influence full adoption of a technology standard. We used Gallivan's (2001) conceptual framework, which models secondary adoption of information technology more broadly, to understand secondary adoption of technology standards in archives, using PREMIS as an example of a technology standard.

Based on interviewee responses, we found that a variety of factors and processes seem to drive PREMIS secondary adoption. In terms of factors, there were similarities and differences among the organizations highlighted in this study, such as the level of management support, resource commitments, and assumptions about how to attain a skilled workforce with programming and development expertise. In terms of processes, there were also similarities and differences among organizations. Only two organizations $(\mathrm{O} 7, \mathrm{O} 8)$ experienced all of the implementation stages (e.g., initiation, adoption, adaptation, acceptance, experimentation, routinization, and infusion). The others were not far enough along in the implementation process to have experienced some of the latter stages (O1, O2, O3, and O9). All organizations followed whatever stages sequentially. This suggests that the outcomes and lessons learned from each stage of the implementation process were important and built upon each other in meaningful ways.

By comparing data across these organizations, we have identified several themes: strong support from top management (Theme A), resources committed (Theme B), and cultural norms that encourage experimentation and learning (Theme $\mathrm{C}$ ). These all facilitate secondary adoption. Furthermore, some of these factors are more important at different stages of the secondary adoption process (Theme D).

\begin{tabular}{|l|llll|} 
Journal : Small-ext 10502 & Dispatch : 24-4-2012 & Pages : 29 \\
Article No. : 9179 & $\square$ LE & $\square$ TYPESET \\
MS Code : ARCS183 & $\square$ CP & $\square$ DISK \\
\hline
\end{tabular}


Participants perceived two aspects of implementation approaches as essential to facilitating implementation of PREMIS, corresponding to Themes A and B:

- Theme A. Strong and clearly communicated top management support for PREMIS facilitated implementation-including early stages (.e.g., initiation and adoption) and later stages (e.g. adaptation, acceptance, experimentation, routinization, and infusion).

- Theme B. Resources committed facilitated implementation.

As data from "Factor construct: managerial interventions" suggest, managerial interventions and influence directly affected the adaptation and experimentation stages of PREMIS implementation. Support from managers enabled P8O6 to get a thorough understanding of PREMIS, which, in turn, positively affected PREMIS implementation. Based on the support managers provided, P8O6 developed expertise, which she subsequently used to develop scenarios for appropriate use of PREMIS. She handed off these scenarios to other program staff who then adapted, experimented with, routinized, and infused them. Managers' commitments of additional resources, particularly hiring of new staff for programming and project management, were also key to implementation. As P5O3 mentioned, none of the technical work necessary to adapt, experiment, routinize, and then infuse PREMIS within Organization 3's systems began until they hired P4O3, a programmer.

- Theme C. Cultural norms that encourage experimentation and learning facilitate later stages of implementation.

As data from "Factor construct: subjective norms" suggests, subjective norms facilitate implementation processes, such as adaptation and experimentation. Furthermore, we found that subjective norms come from the top down as well as from peers. The top down norms, though, appear to have more influence. For example, $\mathrm{P} 2 \mathrm{O} 2$ and $\mathrm{P} 3 \mathrm{O} 2$ knew that management expected them to try different things in order to implement PREMIS. P2O2 and P3O2 cited this "fail, but fail quickly" endorsement as influential in their being able to adapt to and experiment with PREMIS in order to get it to work as desired.

- Theme D. Some innovation, organization, and individual attributes do not influence the early stages of secondary adoption (e.g., initiation and adoption); however, they do affect later stages of secondary adoption (e.g., adaptation, acceptance, experimentation, routinization, and infusion).

The fact that PREMIS had the innovation attributes of being flexible and able to complement several other metadata standards proved to be crucial to organizations in getting through the latter stages of implementation, including adaptation, experimentation, routinization, and infusion. During each one of these stages, participants found ways to use PREMIS to complement other metadata standards that in aggregate shaped project/program preservation repository management systems to suit organizations' needs. Participants mentioned specific examples of their use of PREMIS along with other metadata standards which showed how organizations have adapted PREMIS, routinized PREMIS by embedding it within systems and infused PREMIS into their routines in order to keep track of

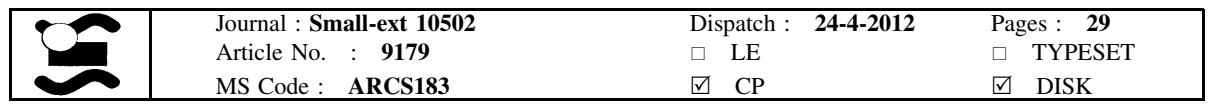


864

865

866

867

868

869

870

871

872

873

874

875

876

877

878

879

880

881

882

883

884

885

886

887

888

889

890

891

892

893

894

895

896

897

898

899

900

901

902

903

904

5FL01

5FL02

5FL03

6FL01

6FL02

provenance, record technical metadata, and link digital objects to rights information more effectively than before (P7O5, P1008, P6O4, P1109, and P8O6).

Although Gallivan designed his framework to explore secondary adoption of information technology more broadly, we used Gallivan's framework to explore secondary adoption of technology standards and found the framework helpful. As evidence from the interview data suggests the organizations included in this study participated or were planning to participate in all of Gallivan's processes of secondary adoption. Factors highlighted in Gallivan's study including managerial interventions, subjective norms, and facilitating conditions also affected organizations. Our data also suggest that certain aspects of Gallivan's model are not relevant and may not apply to PREMIS implementation. We attribute this to a difference between implementing information technology and implementing technology standards. For example, in contrast to managers involved with implementation of information technology (Gallivan 2001 p 66), most managers did not actively provide resources to support training of employees in use of PREMIS. Perhaps this was because PREMIS has more limited organizational applications and at most only a handful of people in any organization would be "using" PREMIS at any one time. Of course, one could also say that managers did not provide training in PREMIS because they did not have the financial resources to provide such training. ${ }^{5}$ Thus, staff responsible for implementation of PREMIS must learn how to use PREMIS "by doing," and learn from staff at other organizations about what does and does not work when trying to implement PREMIS. Staff should also learn from other institutions by analyzing PREMIS in METS application profiles registered on the Library of Congress website. We speculate that, in contrast to information technology, PREMIS is a technology standard that members of the digital preservation community - a community of practice — created for the community (Wenger et al. 2002). As such, members of this community are expected to develop PREMIS based on their experiences, share their experiences with others, and report feedback to the PREMIS Editorial Committee. Perhaps the only support managers could provide to their staff for learning how to use PREMIS would be to pay for at least one of their staff to attend a PREMIS tutorial or implementation fair. ${ }^{6}$ During these events, members of the PREMIS Editorial Committee provide a detailed overview of the PREMIS data dictionary and schema, and current implementers share case studies. Attending these events would enable staff to network, and hopefully keep in touch to help one another through their PREMIS implementation processes.

Of course, each implementer has to read the PREMIS data dictionary and its accompanying XML schema in order to learn how to use PREMIS. However, the data show that learning how to use PREMIS takes much more than this. For example, when asked, "what sorts of things did you do/are you doing to learn how to use PREMIS?" P1109 replied,

\footnotetext{
5 The large firms included in Gallivan's study had millions of dollars to support training for information technology applications, whereas none of the organizations included in this study had that magnitude of resources to devote to training.

${ }^{6}$ For more information about previous and upcoming PREMIS tutorials and implementation fairs go to the PREMIS maintenance activity website at http://www.loc.gov/standards/premis/.
}

\begin{tabular}{|l|llll|}
\hline & Journal : Small-ext 10502 & Dispatch : $\mathbf{2 4 - 4 - 2 0 1 2}$ & Pages : 29 \\
Article No. : $: 9179$ & $\square$ LE & $\square$ & TYPESET \\
MS Code : ARCS183 & $\square$ CP & $\square$ & DISK \\
\hline
\end{tabular}


Table 2 Proposed Model of PREMIS Implementation

\begin{tabular}{|c|c|c|c|c|}
\hline \multirow{2}{*}{$\begin{array}{l}\text { Factors } \\
\text { Themes }\end{array}$} & \multicolumn{2}{|c|}{ Managerial interventions } & \multirow{2}{*}{$\begin{array}{l}\text { Subjective norms } \\
\mathrm{C} \\
\text { cultural norms that } \\
\text { encourage } \\
\text { experimentation }\end{array}$} & \multirow{2}{*}{$\begin{array}{l}\text { Facilitating } \\
\text { conditions } \\
\text { D } \\
\text { Innovation } \\
\text { organization and } \\
\text { individual } \\
\text { attributes }\end{array}$} \\
\hline & $\begin{array}{l}\text { A } \\
\text { strong clear } \\
\text { messages of } \\
\text { management } \\
\text { support }\end{array}$ & $\begin{array}{l}\text { B } \\
\text { measures for } \\
\text { committed } \\
\text { for support }\end{array}$ & & \\
\hline \multicolumn{5}{|l|}{ Processes } \\
\hline Initiation & $\boldsymbol{V}$ & $\boldsymbol{\nu}$ & $\boldsymbol{\nu}$ & \\
\hline Adoption & $\checkmark$ & $\checkmark$ & $\checkmark$ & \\
\hline Adaptation & $\boldsymbol{\nu}$ & $\checkmark$ & $\boldsymbol{V}$ & $\boldsymbol{V}$ \\
\hline Acceptance & $\checkmark$ & $\checkmark$ & $\checkmark$ & $\checkmark$ \\
\hline Experimentation & & & & $\checkmark$ \\
\hline Routinization & & & & $\checkmark$ \\
\hline Infusion & & & & $\checkmark$ \\
\hline
\end{tabular}

The table is a modified version of Gallivan's "secondary adoption and organizational assimilation processes" (see the center of Fig. 1) adapted to account for the context of PREMIS implementation

you mean aside from reading the spec, and doing the paper exercises, and then doing a prototype? [...] we had to make sure that when we created the METS thing, that it actually, that the schema worked, and that it vetted okay. If you think about that, having to vet against METS and PREMIS and ISO all at the same time, there were some issues with that.

Simply put, implementers must also experiment with PREMIS in order to learn how to use it and to learn how to best apply it in their organizations. Then, implementers can routinize and infuse PREMIS in organizational systems. Based on our findings, we modified Gallivan's framework, adding the experimentation construct because of its importance in the context of secondary adoption of technology standards.

Table 2 presents a detailed model incorporating data as well as the themes and constructs that emerged from this study, such as experimentation, along with constructs derived from Gallivan's framework. In our adapted model, we attempt to describe the relationships between the factors and processes involved in the secondary adoption of PREMIS.

Managers send strong and clear messages of support and commit resources to support PREMIS implementation. These attributes, in turn, can induce implementers to commit to the adaptation of PREMIS within an organization's systems. Cultural norms, which reinforce experimentation and learning, can also positively affect experimentation and adaptation, which, in turn, affects routinization and infusion.

Innovation, organizational, and individual attributes also contribute to adaptation, acceptance, experimentation, routinization, and infusion. For example, participants identified PREMIS as lending itself to meeting key information needs for organizations interested in preserving digital objects by being designed to represent relationships among digital objects as well as to document specific preservation

\begin{tabular}{|l|llll|}
\hline & Journal : Small-ext 10502 & Dispatch : $\mathbf{2 4 - 4 - 2 0 1 2}$ & Pages : 29 \\
Article No. : $: 9179$ & $\square$ LE & $\square$ & TYPESET \\
& MS Code : ARCS183 & $\square$ CP & $\square$ & DISK \\
\hline
\end{tabular}


930

931

932

933

934

935

936

937

938

939

940

941

942

943

944

945

946

947

948

activities. They also perceived PREMIS as agile in that it can complement other standards that organizations use. Finally, we found that organizations with flexible preservation repository management systems, those not yet in the production phase of development of their preservation repository management systems, or those in the process of creating new preservation repository systems and software, are all able to adapt PREMIS and engage in secondary adoption of PREMIS more easily.

What does it mean to adopt a technology standard? In the case of PREMIS, it does not mean that an institution has to use the entire data dictionary or data model. Looking to DOI and MIS literature affords archivists the opportunity to define what it means to adopt a technology standard more concretely. Using our framework adapted from Gallivan (2001), archivists now have a means of understanding implementation as a process as well as a definition for a secondary adopter-one who still desires to adopt a technology standard after successfully completing all processes related to secondary adoption, including: initiation, adoption, adaptation, acceptance, experimentation, routinization, and infusion. The reason the definition of secondary adopter has to be qualified as one who still desires to adopt a technology standard after successfully completing all secondary adoption processes is because sometimes, as P7O5 demonstrates, the result of completion of any one or combination of secondary adoption processes is to undo primary adoption.

\section{Conclusion}

In this article, we applied the phenomenon of secondary adoption to technology standards. What we found is that there are differences between the implementation of IT and implementation of technology standards. While we cannot generalize our findings to all technology standards, we do propose refinements to Gallivan's (2001) existing hybrid factor/process model which illustrate the complex relationships between factors and processes in the case of PREMIS. By refining this hybrid framework, this article suggests a complex and, hopefully, a more realistic framework that can explain the interplay among organizational context variables, attributes of managers' implementation strategies, and other characteristics that, in aggregate, shape secondary adoption of technology standards (as shown in Table 2). This article also offers a rich description of multiple organizations implementing PREMIS - an important technology standard for preservation metadata. Many institutions have made the primary adoption decision to adopt PREMIS (Alemneh 2009), but few have yet fully implemented it.

Moving forward, we propose three recommendations for managers and implementers with respect to secondary adoption of PREMIS. First, provide positive managerial interventions. Not every institution is able to hire new staff, but managers can support existing staff by encouraging experimentation and multiple venues for learning during adaptation. Second, retain flexibility in one's preservation repository management systems beyond the prototyping stage and into production to extend the experimentation period and allow for better infusion. Third, it takes a village. View the PREMIS implementation community as a learning community. Strengthen ties between PREMIS implementers and encourage

\begin{tabular}{|l|llll|}
\hline & Journal : Small-ext 10502 & Dispatch : $\mathbf{2 4 - 4 - 2 0 1 2}$ & Pages : 29 \\
Article No. : $: 9179$ & $\square$ LE & $\square$ & TYPESET \\
& MS Code : ARCS183 & $\square$ CP & $\square$ & DISK \\
\hline
\end{tabular}


973

974

975

976

977

978

979

980

981

982

983

984

985

986

987

988

989

990

991

992

993

994

995

996

997

998

999

1000

1001

1002

1003

1004

1005

1006

1007

1008

1009

1010

1011

1012

1013

1014

registration on the Library of Congress PREMIS Implementers Group and participation in the PIG listserv. Register application profiles of PREMIS in METS on the Library of Congress website. Sharing both positive and negative information about the implementation and particularly the experimentation process will benefit all institutions engaged in the secondary adoption process.

Most importantly, we argue that this study underscores the value of using theoretical frameworks from DOI and MIS to better understand the social and technical issues archivists face while implementing technology standards. In our case, using Gallivan's framework required a bit of adaptation to suit an archival context. Nonetheless, using Gallivan's framework was helpful for understanding implementation as a process, specifically for the processes that embody it and the factors that affect it. We believe our study demonstrates that DOI and MIS offer methodologies and diagnostic tools for assessing implementation of technology standards as a process and archivists ought draw on these rich and well-developed methodologies. PREMIS is not the first technology standard archivists have had to adopt and embed in their preservation systems, and it certainly will not be the last. Therefore, it is to the benefit of archival scholars and practitioners to draw upon established methodologies for implementation and adapt them to analyze implementation as a process in archival settings. Future studies could test our model to gauge its effectiveness in exploring implementation of other technology standards in archives.

As with any study, there are limitations. In this study, we focused on institutions that have decided to adopt PREMIS. This study does not research why institutions did not adopt PREMIS. Future studies could explore why institutions decided not to adopt PREMIS. Also, it is difficult to know how many organizations are actually implementing PREMIS. Those listed on the PREMIS Implementation Registry must initiate the registration process. Consequently, there could be many institutions that are PREMIS implementers, but for whatever reason, decided not to initiate the registration process, and therefore are not listed. This limits the extent to which we can make generalizable claims about PREMIS implementers. Nevertheless, we do think our study has value in addressing the issue of implementation of technology standards. Whether or not we have a true representation of PREMIS implementers does not change the fact that we need methodologies to understand implementation of technology standards as a process, which is the primary aim of this paper.

\section{Appendix: interview protocol}

\section{Section 1}

(1) What is your institution's mission with respect to preservation of digital objects?

(2) What information does your institution think is important to know about each of the digital objects you are responsible for preserving?

(3) What did you use before using PREMIS? How does PREMIS compare to what you were using before?

(4) What metadata standards or schemes do you use at your institution?

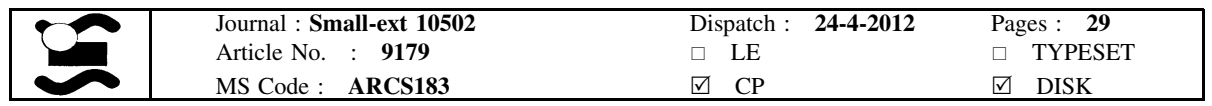


1015 Section 2

1016 (5) What do you use PREMIS for?

(6) Who made the decision to adopt PREMIS at your institution?

(7) For how long have you been implementing PREMIS at your institution?

(8) How does PREMIS interact with the other metadata standards you are using (i.e., such as METS)?

(9) How many staff members are responsible for implementing PREMIS at your institution?

(10) How would you describe the PREMIS implementation process at your institution (i.e., what steps are involved in the implementation of PREMIS at your institution)?

(11) How easy or difficult has it been to use PREMIS to represent information that your institution thinks is necessary for preserving digital objects?

(12) Are your institution's policies for preservation of digital objects reflected in your institution's current implementation of PREMIS? (Please provide examples)

1030

1031

1032

1033

1034

1035

1036

1037

1038

1039

1040

1041

1042

1043

1044

1045

(13) How does your manager support use of PREMIS at your institution?

(14) What sorts of things did you do/are you doing to learn how to use PREMIS?

(15) Does using PREMIS make your job easier/better?

(16) Does using PREMIS advance your institution's goals with respect to preservation of digital objects? How so?

(17) Is PREMIS embedded in your institution's preservation systems and protocols?

(18) What sorts of activities do you do to make sure that PREMIS is "working" as you desired or hoped it would?

(19) Is there anything that PREMIS does not do that you wish it could do?

(20) How often do you utilize resources on the Library of Congress' PREMIS Maintenance Activity website?

(21) Are you a member of the PREMIS Implementers' Group, a free listserv called the PIG list?

1047

1048

1049

1050

1051

1052

1053

1054

1055

1056

1057

1058

1059

\section{References}

Agarwal R (2000) Individual acceptance of information technologies. In: Zmud RW (ed) Framing the domains of IT management: projecting the future through the past. Pinnaflex Press, Cincinnati, pp 85-104

Ajzen I, Fishbein M (1980) Understanding attitudes and predicting social behavior (Pbk ed.). PrenticeHall, Englewood Cliffs, N.J

Alemneh DG (2009) Barriers to adopting PREMIS in cultural heritage institutions: an exploratory study. Archiving 2009, Arlington, Virginia, pp 111-118

Caplan P (2009) Understanding PREMIS. Washington, DC: Library of Congress. Retrieved from http://www.loc.gov/standards/premis/understanding-premis.pdf

Consultative Committee for Space Data Systems (CCSDS) (2002) Reference model for an open archival information system (OAIS) recommendation for space data system standards; blue book. Washington, DC: CCSDS Secretariat. Retrieved from: http://public.ccsds.org/publications/archive/ 650x0b1.pdf

\begin{tabular}{|l|llll|}
\hline & Journal : Small-ext 10502 & Dispatch : 24-4-2012 & Pages : 29 \\
Article No. : 9179 & $\square$ LE & $\square$ TYPESET \\
MS Code : ARCS183 & $\square$ CP & $\square$ & DISK \\
\hline
\end{tabular}


1060

1061

1062

1063

1064

1065

1066

1067

1068

1069

1070

1071

1072

1073

1074

1075

1076

1077

1078

1079

1080

1081

1082

1083

1084

1085

1086

1087

1088

1089

1090

1091

1092

1093

1094

1095

1096

1097

1098

1099

1100

1101

1102

1103

1104

1105

1106

1107

1108

1109

1110

1111

1112

1113

1114

1115

1116

1117

Conway P (1996) Preservation in the digital world. Washington DC: Commission on Preservation and Access. Retrieved from http://www.clir.org/pubs/reports/conway2/

Cooper RB, Zmud RW (1990) Information technology implementation research: a technological diffusion approach. Manage Sci 36(2):123-139

Corbin JM, Strauss AL (2008) Basics of qualitative research: techniques and procedures for developing grounded theory. SAGE Publications, Los Angeles

Dappert A, Enders M (2008) Using METS, PREMIS, and MODS for archiving eJournals. D-Lib Magazine 14(10) Retrieved from http://www.dlib.org/dlib/september08/dappert/09dappert.html

Davis FD, Bagozzi RP, Warshaw PR (1989) User acceptance of computer technology: a comparison of two theoretical models. Manage Sci 35(8):982-1003

Donaldson DR, Conway P (2010) Implementing PREMIS: a case study of the Florida digital archive. Library Hi Tech 28(2):273-289

Duff W (2004) Metadata in Digital Preservation: Foundations, Functions and Issues. In: Bischoff FM, Hofman H, Ross S (eds) Metadata in preservation: selected papers from an ERPANET seminar at the archives school Marburg pp. 27-38

Fichman RG, Kemerer CF (1999) The illusory diffusion of innovation: an examination of assimilation gaps. Inf Syst Res 10(3):255-275

Gallivan MJ (2001) Organizational adoption and assimilation of complex technological innovations: development and application of a new framework. Database Adv Inf Syst 32(3):51

Garrett J, Waters D (1996) Preserving digital information: report of the task force on archiving of digital information. Washington, DC: Council on Library and information Resources. Retrieved from http://www.clir.org/pubs/reports/pub63watersgarrett.pdf

Guenther R, Xie Z (2007) Implementing PREMIS in container formats. Archiving 2007, Arlington, Virginia

Hofman H (2005) The use of standards and models. In: McLeod J, Hare C (eds) Managing electronic records. Facet, London, pp 18-33

Kenney AR, Rieger OY (2000) Preserving digital assets: Cornell's Digital Image Collection Project. First Monday 5(6): 5 June 2000

Klein HK, Myers MD (1999) A set of principles for conducting and evaluating interpretive field studies in information systems. MIS Q 23(1):67-93

Leonard-Barton D (1988) Implementation as mutual adaptation of technology and organization. Res Policy 17(5):251-267

Leonard-Barton D, Deschamps I (1988) Managerial influence in the implementation of new technology. Manage Sci 34(10):1252-1265

Library of Congress (2011) Index to registered METS profiles. Metadata encoding and transmission standard official website. Retrieved from: http://www.loc.gov/standards/mets/mets-divTree.html

Miles MB, Huberman AM (1994) Qualitative data analysis: an expanded sourcebook, 2nd edn. Sage Publications, Thousand Oaks

OCLC/RLG Working Group on Preservation Metadata (2002) Preservation metadata and the OAIS information model: a metadata framework to support the preservation of digital objects. Dublin, Ohio: OCLC. Retrieved from http://www.oclc.org/research/activities/past/orprojects/pmwg/pm_ framework.pdf

Orlikowski WJ (1993) CASE tools as organizational change: investigating incremental and radical changes in systems development. MIS Q 17(3):309

PREMIS Editorial Committee (2010) Conformant implementation of the PREMIS data dictionary. Washington, DC: Library of Congress. Retrieved from http://www.loc.gov/standards/premis/ premis-conformance-oct2010.pdf

PREMIS Editorial Committee (2011) PREMIS data dictionary for preservation metadata version 2.1. Washington, DC: Library of Congress. Retrieved from http://www.loc.gov/standards/premis/v2/ premis-2-1.pdf

PREMIS Maintenance Activity (2010) PREMIS implementation registry. Retrieved March 15, 2011, from http://www.loc.gov/standards/premis/premis-registry.php

PREMIS Working Group (2005) Data dictionary for preservation metadata: final report of the PREMIS Working Group. Washington, DC: Library of Congress. Retrieved from http://www.oclc.org/ research/activities/past/orprojects/pmwg/premis-final.pdf

Prescott MB, Conger SA (1995) Information technology innovations: a classification by IT locus of impact and research approach. SIGMIS database 26(2-3):20-41

Rogers EM (2003) Diffusion of innovations. Free Press, New York

Springer

\begin{tabular}{|l|llll|}
\hline & Journal : Small-ext 10502 & Dispatch : $\mathbf{2 4 - 4 - 2 0 1 2}$ & Pages : 29 \\
Article No. : $: 9179$ & $\square$ LE & $\square$ & TYPESET \\
MS Code : ARCS183 & $\square$ CP & $\square$ & DISK \\
\hline
\end{tabular}


1118

1119

1120

1121

1122

1123

1124

1125

1126

1127

1128

1129

1130

1131

1132

1133

1134

1135

1136

1137

1138

1139

1140

1142

1143

1144

1145

1146

1147

1148

1149

1150

1151

1152

1153

1154

1155

1156

1157

1158

1159

1160

1161

1162

1163
Saga VL, Zmud RW (1994) The nature and determinants of IT acceptance, routinization, and infusion. In: Proceedings of the IFIP TC8 working conference on diffusion, transfer and implementation of information technology, pp 67-86

Shaw T, Jarvenpaa SL (1997) Information systems and qualitative research. In: Proceedings of the IFIP TC8 WG 8.2 international conference on information systems and qualitative research, pp 70-100

Van de Ven A (1986) Central problems in the management of innovation. Manage Sci 32(5):590-607

Vermaaten S (2010) A checklist and a case for documenting PREMIS-METS decisions in a METS profile. D-Lib Magazine 16(9/10) doi:http://www.dlib.org/dlib/september10/vermaaten/ 09vermaaten.html

Wenger E, McDermott RA, Snyder W (2002) Cultivating communities of practice: a guide to managing knowledge. Harvard Business School Press, Boston, Mass

Wilson A (2004) Too many metadata standards? The Australian experience. In: Bischoff FM, Hofman H, Ross S (eds) Metadata in preservation: selected papers from an ERPANET seminar at the archives school Marburg, pp 119-132

Woodyard-Robinson D (2007) Implementing the PREMIS data dictionary: a survey of approaches. Washington DC: Library of Congress. Retrieved from http://www.loc.gov/standards/premis/ implementation-report-woodyard.pdf

Zaltman G, Duncan R, Holbek J (1973) Innovations and organizations. Wiley, New York

Zmud RW (2000) Framing the domains of IT management: projecting the future- through the past. Pinnaflex Education Resources, Inc., Cincinnati, Ohio

\section{Author Biographies}

Devan Ray Donaldson is a Doctoral Candidate in the School of Information at the University of Michigan, Ann Arbor. He conducts research in the areas of digital preservation and curation focusing on preservation management, preservation metadata, preservation repositories and users. Recent publications include "Users' Trust in Trusted Digital Repository Content" in the proceedings of the $8^{\text {th }}$ International Conference on the Preservation of Digital Objects (iPres 2011), "Provenance, End-User Trust, and Reuse: An Empirical Investigation" with Kathleen Fear in the proceedings of the $3^{\text {rd }}$ USENIX Workshop on the Theory and Practice of Provenance (TaPP 2011) and "Implementing PREMIS: A Case Study of the Florida Digital Archive" with Dr. Paul Conway in Library Hi Tech. Donaldson has been a Bill and Melinda Gates Millennium Scholar since 2002, a Horace H. Rackham Merit Fellow since 2008 and an Edward Alexander Bouchet Graduate Honor Society Member since 2012. He earned a M.S. in Library Science from the University of North Carolina and a B.A. in History from the College of William and Mary in Virginia.

Elizabeth Yakel is a Professor in the School of Information at the University of Michigan, Ann Arbor where she teaches in the Archives and Records Management specialization and serves as coordinator for the new Preservation of Information specialization. Her research interests include access to primary sources and user information behavior in archives, particularly digital archives. Recently, Yakel has been investigating how social computing/Web 2.0 applications affect access to archives through the Polar Bear Expedition Digital Collections. Her other major research project concerns Archival Metrics and creating standardized assessment and reporting tools for archivists. Yakel's research has been supported by the National Historical Publications and Records Commission, the Institute for Museum and Library Services, and the Andrew W. Mellon Foundation. She has been active in the Society of American Archivists (SAA), served on its governing council, and was elected an SAA Fellow in 1999.

\begin{tabular}{|l|llll|}
\hline & Journal : Small-ext 10502 & Dispatch : 24-4-2012 & Pages : 29 \\
Article No. : 9179 & $\square$ LE & $\square$ TYPESET \\
MS Code : ARCS183 & $\square$ CP & $\square$ DISK \\
\hline
\end{tabular}

